REGARDS

SUR L'ECONOMIE ALLEMANDE

BULLETIN ECONOMIQUE DU CIRAC
Regards sur l'économie allemande

Bulletin économique du CIRAC

$84 \mid 2007$

Varia

\title{
Marché de l'énergie
}

BERGER Ariane, Staatseigenschaft gemischtwirtschaftlicher Unternehmen. Eine Untersuchung der staatlichen Qualität unternehmerischer Entscheidungen / BOHNE Eberhard, JANSEN Dorothea (eds), Strategien von Stadtwerken im liberalisierten Strommarkt / Die Energiepolitik zwischen Wettbewerbsfähigkeit, Versorgungssicherheit und Nachhaltigkeit / FRENZEL Sabine, Stromhandel und staatliche Ordnungspolitik

\section{CpenEdition} Journals

Édition électronique

URL : http://journals.openedition.org/rea/422

DOI : $10.4000 /$ rea. 422

ISBN : 978-2-8218-0864-5

ISSN : 1965-0787

Éditeur

CIRAC

Édition imprimée

Date de publication : 1 décembre 2007

ISSN : 1156-8992

Référence électronique

"Marché de l'énergie », Regards sur l'économie allemande [En ligne], 84 | décembre 2007, document 6, mis en ligne le 22 avril 2008, consulté le 22 septembre 2020. URL : http://journals.openedition.org/rea/ 422 ; DOI : https://doi.org/10.4000/rea.422

Ce document a été généré automatiquement le 22 septembre 2020

(c) CIRAC 


\section{Marché de l'énergie}

BERGER Ariane, Staatseigenschaft gemischtwirtschaftlicher

Unternehmen. Eine Untersuchung der staatlichen Qualität unternehmerischer Entscheidungen / BOHNE Eberhard, JANSEN

Dorothea (eds), Strategien von Stadtwerken im liberalisierten

Strommarkt / Die Energiepolitik zwischen Wettbewerbsfähigkeit, Versorgungssicherheit und Nachhaltigkeit / FRENZEL Sabine, Stromhandel und staatliche Ordnungspolitik

\section{RÉFÉRENCE}

BERGER Ariane, Staatseigenschaft gemischtwirtschaftlicher Unternehmen. Eine Untersuchung der staatlichen Qualität unternehmerischer Entscheidungen, Coll. Schriften zum öffentlichen Recht, Duncker \& Humblot, Berlin, Berlin, 2006, 288 p. BOHNE Eberhard, JANSEN Dorothea (eds), Strategien von Stadtwerken im liberalisierten Strommarkt, Coll. Schriftenreihe der Hochschule Speyer, Duncker \& Humblot, Berlin, 2007, 132 p.

Die Energiepolitik zwischen Wettbewerbsfähigkeit, Versorgungssicherheit und Nachhaltigkeit, Vierteljahrshefte zur Wirtschaftsforschung, $\mathrm{n}^{\circ}$ 1/2007, DIW Berlin, 162 p.

FRENZEL Sabine, Stromhandel und staatliche Ordnungspolitik, Coll. Schriftenreihe der Hochschule Speyer, Duncker \& Humblot, Berlin, 2007, 378 p.

1 La libéralisation des marchés de l'énergie est un défi pour le politique qui doit établir des règles spécifiques pour une situation de concurrence nouvelle non seulement nationales, mais aussi européennes (FRENZEL). Il s'agit en effet de concilier trois objectifs: compétitivité, sécurité de l'approvisionnement et protection de l'environnement (DIW). La libéralisation pose aussi la question des stratégies que doivent suivre les acteurs sur un marché libéralisé, en particulier ces innombrables régies communales qui exercent le métier d'électricien outre-Rhin (BOHNE et al.). Enfin, quel est le type de statut d'entreprise le plus adéquat? Les modèles d'économie mixte sont-ils adaptés, et comment évaluer plus généralement en droit l'action 
d'acteurs largement publics dans un segment des services qui relève ou va relever désormais du marché (BERGER)? (ib) 